\title{
Volume, distribution and acidity of gastric secretion on and off proton pump inhibitor treatment: a randomized double-blind controlled study in patients with gastro-esophageal reflux disease (GERD) and healthy subjects
}

Andreas Steingoetter ${ }^{1,2^{*}+}$, Matthias Sauter ${ }^{1 \dagger}$, Jelena Curcic ${ }^{1}$, Dian Liu ${ }^{1,2}$, Dieter Menne ${ }^{3}$, Michael Fried ${ }^{1}$, Mark Fox ${ }^{1}$ and Werner Schwizer ${ }^{1}$

\begin{abstract}
Background: Postprandial accumulation of gastric secretions in the proximal stomach above the meal adjacent to the esophagogastric junction (EGJ), referred to as the 'acid pocket', has been proposed as a pathophysiological factor in gastro-esophageal reflux disease (GERD) and as a target for GERD treatment. This study assessed the effect of proton pump inhibitor (PPI) therapy on the volume, distribution and acidity of gastric secretions in GERD and healthy subjects (HS).

Methods: A randomized, double blind, cross-over study in $12 \mathrm{HS}$ and 12 GERD patients pre-treated with $40 \mathrm{mg}$ pantoprazole (PPI) or placebo b.i.d. was performed. Postprandial secretion volume (SV), formation of a secretion layer and contact between the layer and the EGJ were quantified by Magnetic Resonance Imaging (MRI). Multi-channel pH-monitoring assessed intragastric $\mathrm{pH}$.
\end{abstract}

Results: A distinct layer of undiluted acid secretion was present on top of gastric contents in almost all participants on and off high-dose acid suppression. PPI reduced SV (193 ml to $100 \mathrm{ml}$, in HS, $227 \mathrm{ml}$ to $94 \mathrm{ml}$ in GERD; p < 0.01) and thickness of the acid layer ( $26 \mathrm{~mm}$ to $7 \mathrm{~mm}, 36 \mathrm{~mm}$ to $9 \mathrm{~mm}$ respectively, $\mathrm{p}<0.01$ ). No differences in secretion volume or layer thickness were observed between groups; however, off treatment, contact time between the secretion layer and EGJ was 2.6 times longer in GERD compared to HS ( $p=0.012)$. This was not the case on PPI.

Conclusions: MRI can visualize and quantify the volume and distribution dynamics of gastric secretions that form a layer in the proximal stomach after ingestion of a liquid meal. The secretion volume and the secretion layer on top of gastric contents is similar in GERD patients and HS; however contact between the layer of undiluted secretion and the EGJ is prolonged in patients. High dose PPI reduced secretion volume by about $50 \%$ and reduced contact time between secretion and EGJ towards normal levels.

Trial registration: NCT01212614.

* Correspondence: steingoetter@biomed.ee.ethz.ch

${ }^{\dagger}$ Equal contributors

${ }^{1}$ Division of Gastroenterology and Hepatology, University Hospital Zurich,

Raemistrasse 100, CH-8091 Zurich, Switzerland

${ }^{2}$ Institute for Biomedical Engineering, University and ETH Zurich, Gloriastrasse

35, $\mathrm{CH}-8092$ Zurich, Switzerland

Full list of author information is available at the end of the article

(C) 2015 Steingoetter et al. Open Access This article is distributed under the terms of the Creative Commons Attribution 4.0 International License (http://creativecommons.org/licenses/by/4.0/), which permits unrestricted use, distribution, and reproduction in any medium, provided you give appropriate credit to the original author(s) and the source, provide a link to the Creative Commons license, and indicate if changes were made. The Creative Commons Public Domain Dedication waiver (http://creativecommons.org/publicdomain/zero/1.0/) applies to the data made available in this article, unless otherwise stated. 


\section{Background}

Postprandial accumulation of acid secretion in the proximal stomach above the meal adjacent to the esophagogastric junction (EGJ), referred to as the "acid pocket", has been proposed as a pathophysiological factor in gastro-esophageal reflux disease (GERD) [1-4] and a target for GERD treatment [5-9]. The acid pocket is described in $\mathrm{pH}$ pull-through studies as a region of unbuffered gastric acid ( $>2 \mathrm{pH}$ drop to below $\mathrm{pH} 4$ ) in close proximity to the EGJ [3]. This can be visualized also as a layer of gastric secretion in the proximal stomach on the surface of the meal by $\gamma$-scintigraphy and Magnetic Resonance Imaging (MRI) [10-13]. Studies combining $\mathrm{pH}$-monitoring and $\gamma$ scintigraphy have shown that the acid pocket is the source of acid reflux early after meal ingestion $[1,7,12]$. Moreover the proximal border of the acid pocket has been shown to encroach on the EGJ in GERD patients such that acid secretions contact the distal esophageal mucosa. This phenomenon has been associated with the presence of reflux esophagitis and Barrett metaplasia [1-4].

One previous MRI study has shown that acid suppression by PPI reduces gastric content volume after meals in healthy volunteers [14]; however, simple volume measurements cannot differentiate between effects of PPI on gastric secretion and gastric emptying. Moreover if the acid pocket hypothesis is correct then it is not necessarily increased secretion volume but rather the abnormal distribution of unbuffered gastric secretions at the EGJ that increases the risk of acid reflux and mucosal disease in GERD patients.

The first objective of this study was to test the hypothesis that, compared to healthy subjects, there is abnormal distribution of gastric secretion in GERD patients that leads to prolonged contact between unbuffered acid and the EGJ after the meal. The second objective was to complete a randomized, placebocontrolled trial to document the effects of PPI on the volume, distribution and acidity of the gastric secretion layer and how this impacts on gastro-esophageal reflux after the meal.

\section{Methods}

This clinical study was approved by the local ethics committee and registered at ClinicalTrial.gov (NCT01212614). Written informed consent was obtained prior to inclusion.

\section{Study design and test meal}

Healthy subjects (HS) and GERD patients without large hiatus hernia were investigated in a randomized, double blind, crossover, placebo controlled study performed at the University of Zurich and the Klinik Stephanshorn, St.Gallen, Switzerland, from December 2010 to December 2011. For study participant allocation, a computergenerated list of the study sequence was generated by an investigator with no clinical involvement in the trial (DM). Participants and investigators were blinded to randomization during data acquisition and analysis. The pantoprazole and placebo were in capsule form and identical in appearance. They were pre-packed in bottles and consecutively numbered for each participant according to the randomization schedule. The protocol (Fig. 1) included a MRI and $\mathrm{pH}$-monitoring session in each study arm on consecutive days. Due to the MRI incompatibility of the $\mathrm{pH}$ monitoring device, $\mathrm{pH}$ studies were performed the day after MRI following the exact same time schedule of drug intake, test meal and body position. For GERD patients, there was a 7 day run-in phase without PPI or $\mathrm{H}_{2}$-Antagonists. Before each study session, subjects received one week of pantoprazole $40 \mathrm{mg}$ b.i.d. or placebo. The two treatment arms were separated by a wash-out phase of 7-10 days. An antacid formula was provided (Riopan Gel ${ }^{\circ}$, Takeda Pharma AG, Switzerland) as rescue medication except for the examination days.

For each session, subjects arrived after a minimum $6 \mathrm{~h}$ fasting period at the study center. Study medication was taken and 45 to 60 min later subjects drank a secretion stimulating test meal in sitting position within $2 \pm 1 \mathrm{~min}$, The test meal was designed to promote gastric secretion and consisted of an acid stable, high caloric, viscous chocolate drink ( $400 \mathrm{ml}, 450 \mathrm{kcal}, \mathrm{pH}$ 5.4) labelled with $167.5 \mu \mathrm{M}$ of MR contrast agent (DOTAREM ${ }^{\circ}$ ) as described and validated previously [13].

\section{Population}

Healthy, asymptomatic subjects (HS) with no history of digestive diseases and without reflux symptoms were recruited by advertisement. GERD patients were recruited from individuals referred for investigation of typical GERD symptoms (i.e. heartburn and/or regurgitation) of at least moderate severity (i.e. at least twice a week of at least moderate intensity) on the Eraflux questionnaire [15, 16]. GERD was diagnosed either by endoscopy confirming an erosive reflux disease (Stage A-C LA Classification) or pathological esophageal acid exposure in $24 \mathrm{~h} \mathrm{pH}-$ monitoring performed within the previous 12 months (more than $4 \%<\mathrm{pH} 4$ over $24 \mathrm{~h}$ ). None had history of upper gastrointestinal surgery. GERD patients were studied after being off acid suppressive medications for at least 7 days prior to study start. Exclusion criteria for both groups were prior abdominal surgery (except appendectomy, inguinal hernia repair), and intake of medication other than oral contraception. A Helicobacter $-{ }^{13} \mathrm{C}$-breath test was performed to rule out Helicobacter pylori infection. High resolution esophageal manometry (HRM) was performed to rule out hiatal hernia $>3 \mathrm{~cm}$ or esophageal motility disorders and to measure the distance from the nares to the lower esophageal sphincter (LOS) for $\mathrm{pH}-$ probe placement. 


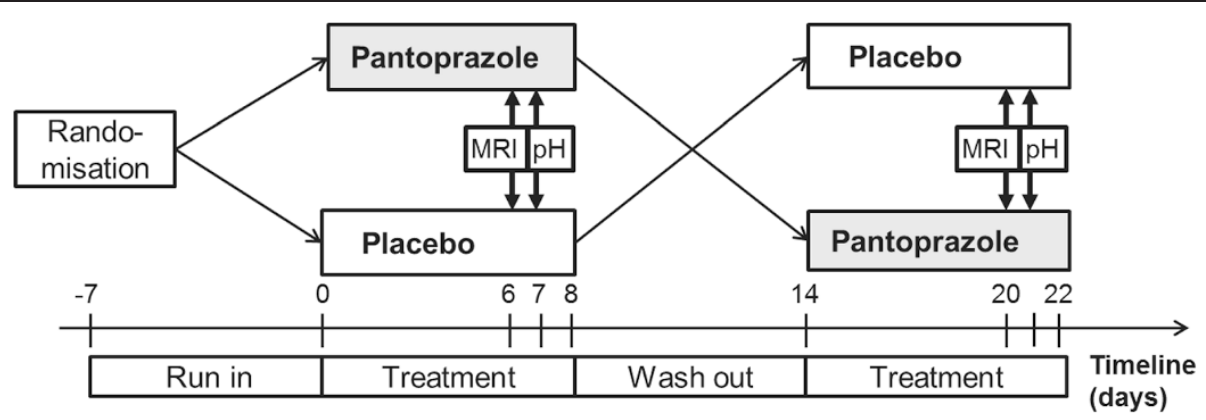

Fig. 1 Flow chart of the double blind, crossover placebo controlled study

\section{MRI measurements}

Participants were imaged in right decubitus body position inside a $1.5 \mathrm{~T}$ clinical MRI System (1.5 T Achieva, Philips Medical Systems, The Netherlands) [13]. After a first MRI scan in fasting condition and the intake of the test meal, a MRI gastric volume scan followed by a validated $\mathrm{T}_{1}-\mathrm{B}_{1}$ mapping sequence (gastric secretion scan) were repeatedly performed at $10 \mathrm{~min}$ intervals until $120 \mathrm{~min}$ [17]. Details on the MRI sequence parameters of the gastric volume and secretion scans can be found in the Additional file 1.

\section{pH monitoring}

Intragastric and esophageal $\mathrm{pH}$ were simultaneously measured using a 3 channel $\mathrm{pH}$ catheter consisting of three ISFET probes (UNISENSOR AG, Switzerland), connected to a $\mathrm{pH}$ recorder from MMS International (Medical Measurement Systems B.V., The Netherlands). The three gastric $\mathrm{pH}$ probes were located 3,8 and $13 \mathrm{~cm}$ distal to the LOS, respectively. After placement of the $\mathrm{pH}$ catheter, the participants drank the test meal and spent $120 \mathrm{~min}$ in right decubitus position to copy the MRI session.

\section{Symptom scores}

Symptoms were recorded before each MRI session. Heartburn, retrosternal pain, regurgitation and dysphagia were assessed and graded by their weekly and daily frequency, duration and intensity. The Eraflux score was applied to quantify the severity of GERD. Response was defined as an Eraflux score of $<25[15,16]$.

\section{Data analysis}

\section{MRI meal and secretion volume}

Gastric content volume (GCV), meal volume (MV) and secretion volume (SV) were derived by combining the gastric volume and secretion data according to previously reported procedures using in-house written software tools based on MATLAB 7.11 (The MathWorks, USA) and IDL (Exelis Visual Information Solutions, USA), respectively $[13,17]$.
In short, first the percentage of intragastric MV (\%meal) from total GCV, measured in the gastric volume scans, was calculated for each time point using the exponential relationship between the $T_{1}$ relaxation time, measured in the gastric secretion scans and the MR contrast agent concentration $[\mu M]$ in the meal:

$$
\% \text { meal }=\frac{100 \%}{167.5 \mu M} \cdot \frac{1}{\beta} \cdot \ln \left(\frac{T_{10}}{T_{1}}\right),
$$

with $\beta=0.013 \mu \mathrm{M}^{-1}$ being the rate constant of the exponential relationship and $T_{10}=2.58 \mathrm{~s}$ being the $\mathrm{T} 1$ relaxation time of the test meal without MR contrast agent. The residual fasted content volume was negligible $(17 \pm 25 \mathrm{ml})$. Thus, $\mathrm{MV}=\mathrm{GCV} \cdot \%$ meal and $\mathrm{SV}=\mathrm{GCV}$ - MV were then calculated and plotted over time to generate the meal emptying and secretion curves. Secretion concentration was defined as \%secretion= 100 - \%meal. Meal emptying curves were fitted using the linear exponential (LinExp) gastric emptying model [18]. Meal half emptying time (t50), mean SV (meanSV) and maximum SV (maxSV) were determined.

To allow the calculation of the EGJ position relative to the acid secretion layer, the position of the EGJ in each gastric volume data set was extracted by selecting $x_{-}$, yand $\mathrm{z}$-coordinates of the intercept of the mid-point of the sphincter mass with gastric content. This is illustrated for two different postprandial time points in the 2D MR images in Fig. $2 \mathrm{a}$ and the respective $3 \mathrm{D}$ reconstructions of stomach and gastric content in Fig. $2 \mathrm{~b}$.

\section{Gastric secretion layer}

The volume and thickness of the gastric secretion layer was extracted from the dedicated gastric secretion scans. The layer was defined as a distinct region in the proximal stomach on top of the gastric contents with \%secretion of $\geq 70 \%$ (i.e. \%meal of $<30 \%$ ). The $70 \%$ secretion threshold was chosen on the basis of in vitro experiments. Serial dilutions of the test meal were performed with $0.1 \mathrm{~N} \mathrm{HCl}^{-}$as a simple surrogate for gastric acid secretions [17]. These experiments determined that 

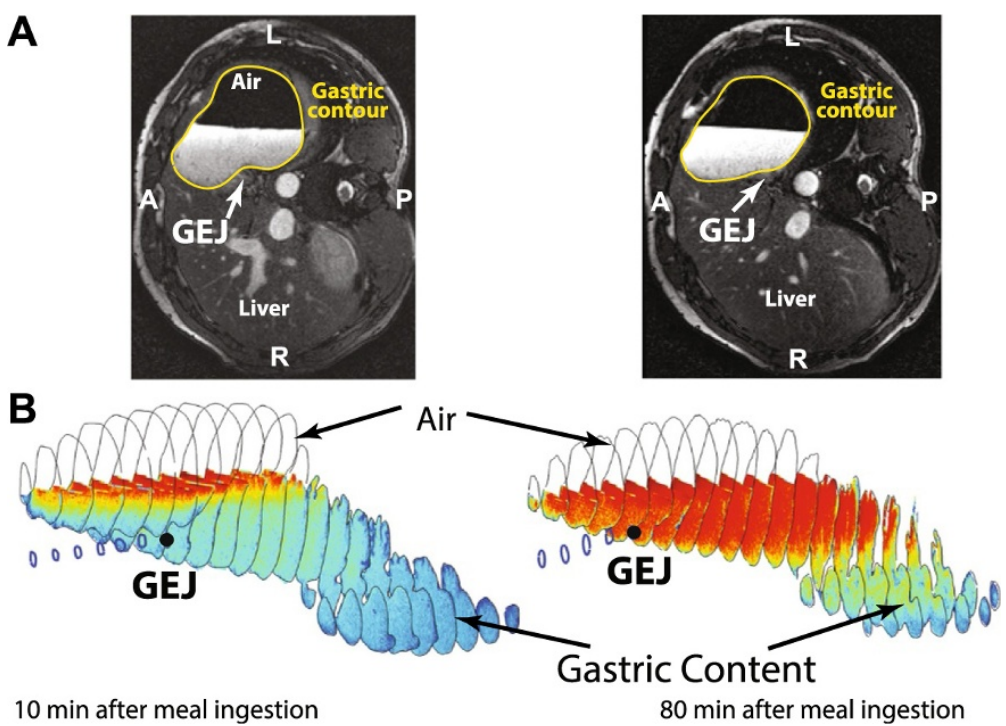

Fig. 2 Definition of the EGJ position and 3D reconstruction of gastric content. a Transverse abdominal MR images at time points $\mathrm{t}=10$ and 80 min. EGJ is marked by a white arrow. Stomach contours are depicted as yellow lines. $\mathbf{b}$ The 3D reconstructed contours of stomach (black closed lines) and esophagus (dark blue closed lines) together with the color-coded gastric content (blue to red) of the same subject at the same time points. Gastric content was color-coded to highlight the formation of the secretion layer, here depicted in red. A non-linear color-coding of the contrast optimized grayscale values in the MR images was applied. The location of the EGJ is marked by the black dot at the end of the esophagus

$\%$ secretion of $\geq 70 \%$ (i.e. \%meal of $<30 \%$ ) resulted in $\mathrm{pH} \leq 2$ in the meal-secretion mixture. This conservative $\mathrm{pH}$ threshold is within that applied in studies that used the $\mathrm{pH}$-sensor pull-through method to define the extent of the acid pocket. Very similar results were obtained in previous studies by titration with gastric secretions obtained at endoscopy [10, 17]. Image processing steps for layer quantification are depicted and explained in Fig. 3.

\section{Contact time between gastric secretion layer and esophagogastric junction (EGJ)}

Layer-graphs (Fig. 7) were produced that integrate information on the formation and position of the gastric secretion layer from secretion scans and the EGJ position from anatomical MRI scans (Figs. 2 and 3). The contact time between the gastric secretion layer \%secretion of $\geq 70 \%$ (i.e. \%meal of $<30 \%$ ) was calculated for each subject. The time to first occurrence of $\geq 70 \%$ secretion at the EGJ was then subtracted from the maximum recording time of $120 \mathrm{~min}$ to obtain the absolute period of contact time. This result was normalized to the subject's t50 to provide an additional assessment of contact time that was independent of emptying dynamics:

\section{Relative_EGJ_contact_timetoLayer$$
=(120 \text { min }- \text { timetofirstLayerformation }) / t 50
$$

This metric describes the contact time of the EGJ with the secretion layer relative to the gastric half emptying time (t50). Thus, values $>1$ indicate that the secretion layer was in contact for more than half the time taken to empty the meal from the stomach. In cases where the EGJ was not exposed to the gastric secretion layer, the time to first occurrence of $\geq 70 \%$ secretion was set to the maximum recording time.

\section{pH monitoring}

Data from $\mathrm{pH}$ monitoring were visually inspected for data quality by MS and WS using the MMS International software tool (Medical Measurement Systems B.V., The Netherlands). Raw data were extracted and analyzed with home-built algorithms implemented in program $R$ ( $R$ Foundation for Statistical Computing, Austria). From the three intragastric $\mathrm{pH}$ - probes, lowest intragastric $\mathrm{pH}$ (mingastricpH) was extracted and median mingastricpH over two hours postprandial were calculated.

\section{Symptom scores}

The severity and frequency of reflux symptoms reported by participants were calculated using the publicly available Eraflux score calculator (http://www.menne-biomed.de/ biomed/erascore2.html) [16].

\section{Statistics}

Statistical analyses were performed using program $\mathrm{R}$ 2.15./RStudio 0.98.274. The LinExp model was computed by population non-linear mixed effect modelling using function nlme [19]. T50 values were numerically derived from parameters $\kappa$ and $t_{\text {empt }}$ as described previously 


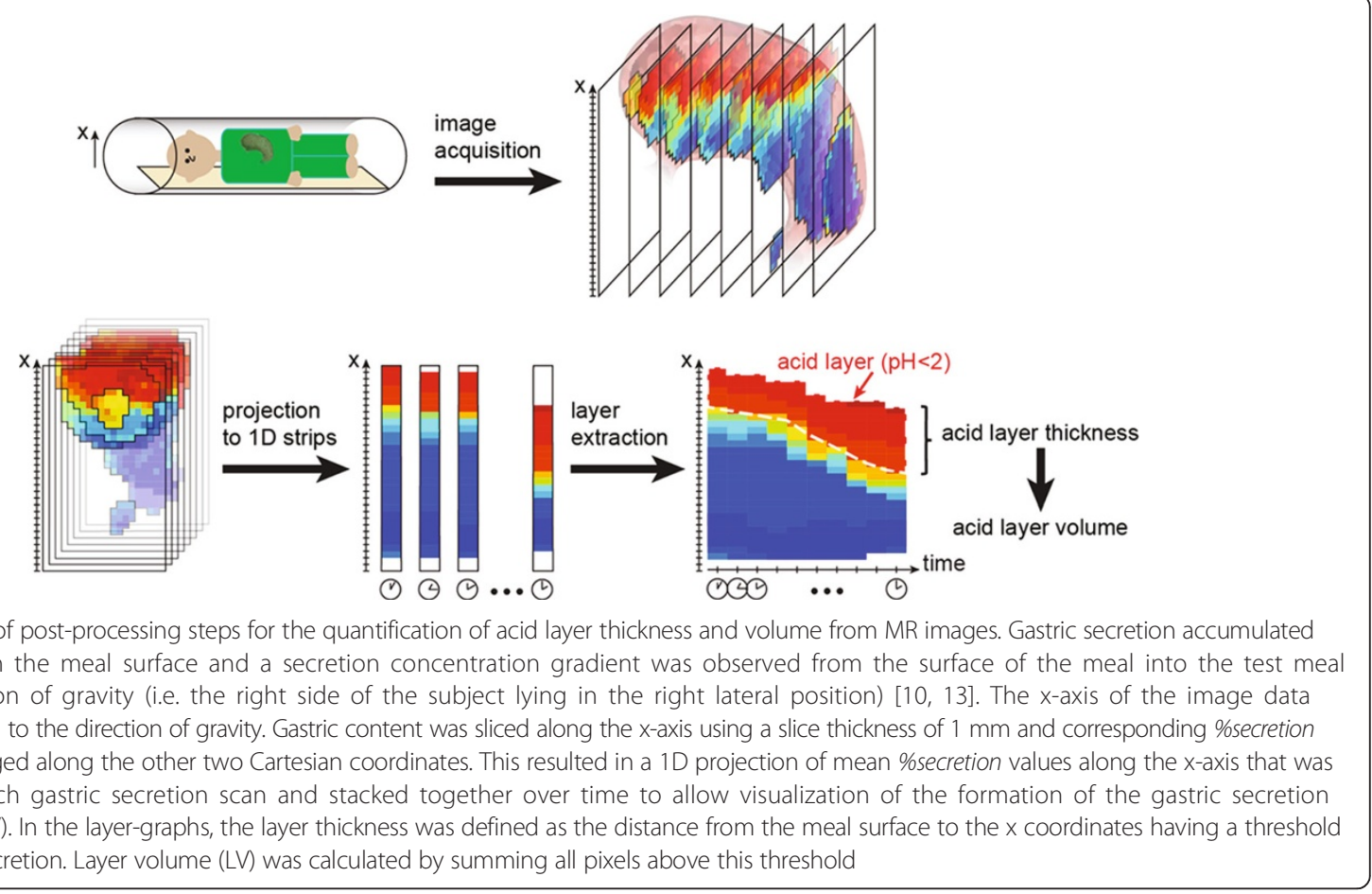

[18]. Univariate linear mixed model analysis using function lme was applied to evaluate the effects of study group and treatment on continuous study parameters. Eraflux scores in GERD patients under placebo and PPI were compared by a linear model using function $l m$ in program $R$. Correlation between SV and LV was performed by linear regression also using function $l m$. Parameter estimates are presented as mean \pm standard error and in case of Poisson distributed data as mean (95\% confidence interval).

\section{Results}

\section{Participants}

Twelve asymptomatic HS (8 m/4w, age $26 \pm 8$ years, BMI $\left.23 \pm 2 \mathrm{~kg} / \mathrm{m}^{2}\right)$ and twelve GERD patients $(7 \mathrm{~m} /$ $5 \mathrm{w}, 45 \pm 11$, BMI $24 \pm 3 \mathrm{~kg} / \mathrm{m}^{2}$ ) were recruited and all completed the study. MRI secretion data from the PPI arm of two GERD patients and $\mathrm{pH}$ data from one HS were discarded due to technical difficulties. Estimates $\pm \mathrm{SE}$ for all investigated parameters are summarized in Table 1.

\section{MRI meal and secretion volumes}

Overall maxSV was approximately $200 \mathrm{ml}$ in both groups under placebo (Table 1) with no difference between groups. PPI treatment reduced maxSV by $93 \pm$ $20 \mathrm{ml}$ in HS and $134 \pm 20 \mathrm{ml}$ in GERD patients, respectively. No difference was observed between study groups in either study arm, all $\mathrm{p} \geq 0.2$. Individual $\mathrm{MV}$ and $\mathrm{SV}$ curves presented by study group and treatment are plotted in Fig. 4. Meal emptying, as assessed by t50, was similar in both study groups (HS vs. GERD) and was not significantly altered by treatment (placebo vs. PPI), all $\mathrm{p}>0.2$.

\section{Gastric secretion layer}

On placebo, gastric secretion accumulated in the proximal stomach forming a distinct secretion layer on top of the meal in 23 of 24 subjects. Variability in secretion layer volume and thickness between subjects was large in both study groups. On PPI, the distinct secretion layer persisted in all but two HS and one GERD patient. Layer formation in each subject for both treatment arms is depicted in Fig. 5.

Layer thickness at $60 \mathrm{~min}$ after the meal decreased on PPI treatment by $19 \pm 1.6 \mathrm{~mm}$ for HS and $27 \pm 1.7 \mathrm{~mm}$ for GERD ( $p<0.0001$ in both groups), with no difference between the study groups (both $\mathrm{p} \geq 0.4$ ). On placebo there was a positive linear correlation between layer volume and secretion volume (Fig. 6). The secretion layer (defined as $\geq 70 \%$ secretions) appeared when approximately $50 \mathrm{ml}$ of secretion accumulated in the stomach and then increased in direct proportion with overall secretion volume.

\section{Contact time between gastric secretion layer and esophagogastric junction (EGJ)}

The layer-graphs of one healthy subject and one GERD patient during the placebo and pantoprazole study arm showing the EGJ position relative to the gastric secretion 
Table 1 Primary and secondary outcome parameter results (data as estimate \pm standard error from the Ime model)

\begin{tabular}{|c|c|c|c|c|c|}
\hline \multirow[t]{2}{*}{ Parameter } & \multirow[t]{2}{*}{ Modality } & \multicolumn{2}{|l|}{$\mathrm{HS}$} & \multicolumn{2}{|l|}{ GERD } \\
\hline & & Placebo & PPI & Placebo & PPI \\
\hline mean SV [ml] & MRI & $133 \pm 14$ & $73 \pm 14^{*}$ & $152 \pm 14$ & $66 \pm 14^{*}$ \\
\hline $\max \mathrm{SV}[\mathrm{ml}]$ & MRI & $193 \pm 17$ & $100 \pm 18^{*}$ & $227 \pm 18$ & $94 \pm 17^{*}$ \\
\hline Layer thickness at $60 \mathrm{~min}[\mathrm{~mm}]$ & MRI & $26 \pm 5$ & $7 \pm 5^{*}$ & $36 \pm 5$ & $9 \pm 5^{*}$ \\
\hline Layer Volume at $60 \mathrm{~min}[\mathrm{ml}]$ & MRI & $79 \pm 16$ & $20 \pm 16^{*}$ & $117 \pm 17$ & $18 \pm 17^{*}$ \\
\hline Median mingastricph & pH-monitoring & $1.8 \pm 0.3$ & $4.5 \pm 0.3^{*}$ & $1.5 \pm 0.3$ & $3.8 \pm 0.3^{*}$ \\
\hline \multicolumn{6}{|l|}{$2 \mathrm{~h}$ postprandial } \\
\hline t50 [min] & MRI & $60 \pm 6$ & $71 \pm 6$ & $62 \pm 6$ & $64 \pm 6$ \\
\hline $\begin{array}{l}\text { EGJ exposure time to } \geq 70 \% \text { secretion } \\
\text { layer Normalized to T50 }\end{array}$ & MRI & $0.45 \pm 0.2$ & $0.42 \pm 0.2$ & $1.18 \pm 0.2^{* * *}$ & $0.42 \pm 0.2^{* *}$ \\
\hline Eraflux symptoms score & Questionnaire & $0 \pm 0$ & $0 \pm 0$ & $33 \pm 3$ & $20 \pm 3^{*}$ \\
\hline
\end{tabular}

${ }^{*}<0.05,{ }^{* *} p<0.01$ different to placebo

*** $<0.05, p<0.01$ different to HS

Poisson distributed parameter

layer are depicted in Fig. 7. For placebo, normalized EGJ contact time to the layer ( $\geq 70 \%$ secretion) relative to gastric half emptying time ( $\mathrm{t} 50$ ) was higher in GERD patients than HS $(p=0.012$, Table 1$)$. This indicates that off medication the EGJ was in contact with the gastric secretion layer for considerably more than half the gastric half emptying time in GERD patients, but for only about half of the half emptying time in HS. Absolute exposure times were $34 \pm 9$ for $\mathrm{HS}$ and $55 \pm 9 \mathrm{~min}$ for GERD on placebo. PPI treatment reduced the normalized contact time to the layer in in GERD patients $(\mathrm{p}=0.03)$ and comparison between groups on acid suppression no longer showed significant differences $(\mathrm{p}=0.9)$. Absolute exposure times on PPI were $21 \pm 9$ for HS and $28 \pm 9$ min for GERD, respectively.

\section{$\mathrm{pH}$ monitoring data}

MingastricpH during the $2 \mathrm{~h}$ after the meal in $\mathrm{HS}$ and GERD patients was $\mathrm{pH} 1.8 \pm 0.3$ and $\mathrm{pH} 1.5 \pm 0.3$, respectively. MingastricpH during the $2 \mathrm{~h}$ postprandial period increased under PPI in HS and GERD patients by $\mathrm{pH} 2.7 \pm 0.4$ and $\mathrm{pH} 2.3 \pm 0.3$, respectively. No difference was detected between study groups (placebo: $\mathrm{p}=0.5$, PPI: $\mathrm{p}=0.1$ ).

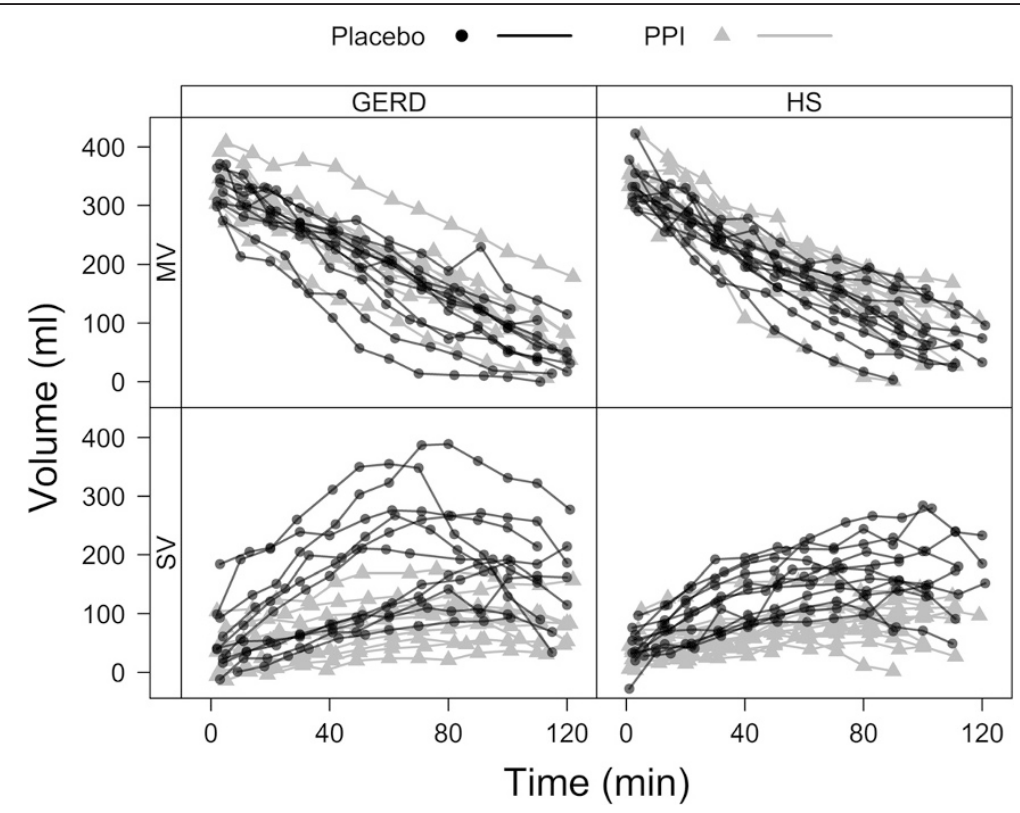

Fig. 4 Grouped meal and secretion volume curves. Meal Volume (MV) and Secretion Volume (SV) dynamics over 120 min for GERD patients and Healthy Subjects (HS), under placebo (black dots/lines) and PPI (grey triangles/lines). The approximately linear emptying pattern of the test meal is typical for a high calorie, viscous liquid meal 


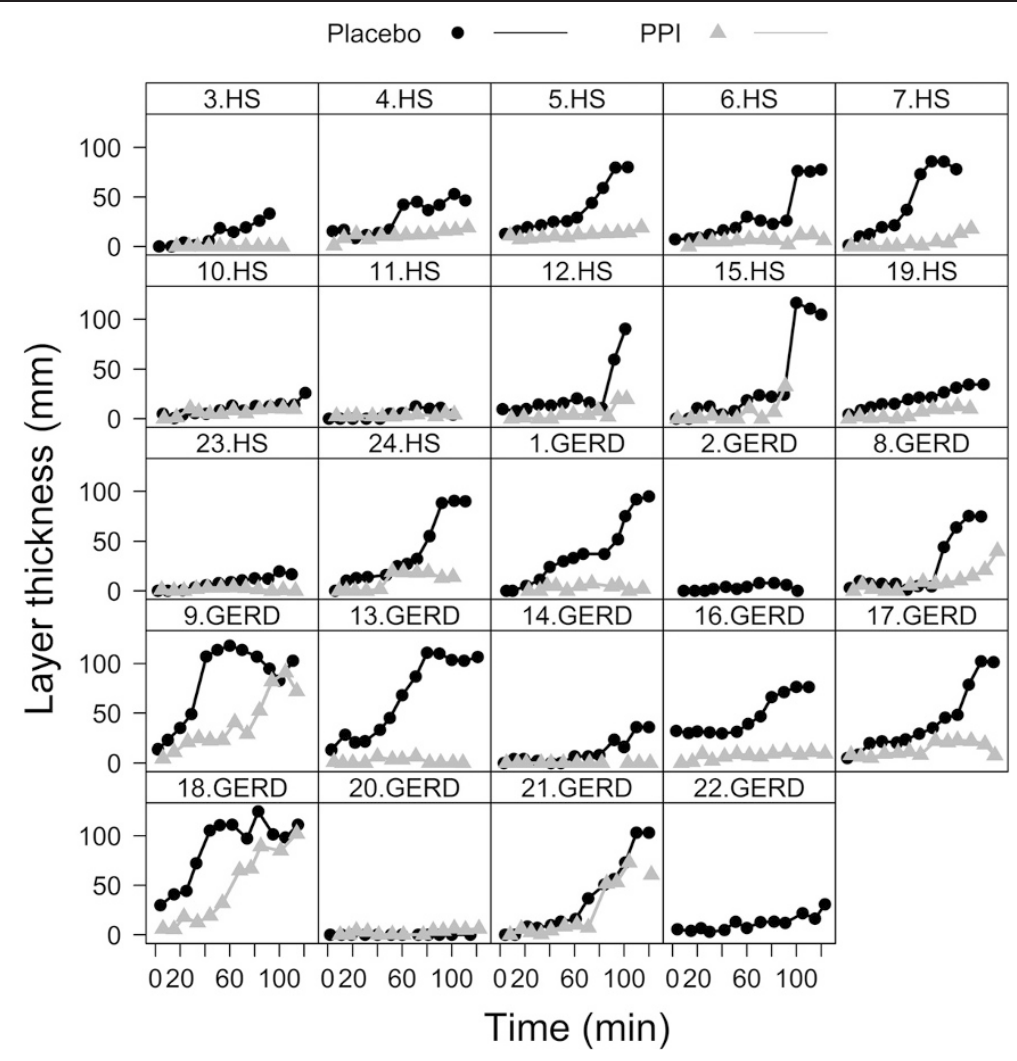

Fig. 5 Formation of individual secretion layers. Layer thickness over time is depicted for all healthy subjects (HS) and GERD patients under placebo (black dots/lines) and PPI therapy (grey triangles/lines)

\section{Symptom scores}

Symptoms improved significantly under PPI in GERD patients. Eraflux symptom scores decreased by $13 \pm 4$ $(\mathrm{p}=0.003)$ with 8 of 12 patients reporting a response, defined as an Eraflux symptom score under PPI below a score of 25 (i.e. one or less symptoms per week of only weak intensity).

\section{Discussion}

This study applied Magnetic Resonance Imaging (MRI) methodology to visualize and quantify the volume and distribution of gastric secretions that form a layer in the proximal stomach after ingestion of a liquid meal. There was no difference in layer formation, secretion volume, intragastric $\mathrm{pH}$, or gastric emptying between healthy subjects and gastroesophageal reflux disease (GERD) patients on placebo. However MRI demonstrated that the distribution of gastric secretions in the stomach was abnormal in the patient group such that the exposure of the EGJ to undiluted gastric secretion was significantly more prolonged than in healthy controls. High dose proton pump inhibitor (PPI) therapy reduced secretion volume, layer thickness and intra-gastric acidity in both healthy subjects and GERD patients; however a persistent layer of gastric secretion was still present in the majority of individuals on acid suppression.

The first objective of this study was to test the hypothesis that, compared to healthy subjects, there is either increased volume or abnormal distribution of gastric secretion in GERD patients. The results demonstrate that collection of undiluted gastric secretion in the proximal stomach after a meal, a key component of the "acid pocket", is a normal physiological phenomenon that occurs in both healthy subjects and GERD patients $[1-3$, 20]. The thickness of the layer documented by MRI was very comparable to the length of the acid pocket after ingestion of a refluxogenic meal on $\mathrm{pH}$ pull-through studies [21]. No differences were observed between the study groups with regard to layer formation, total gastric secretion volume or gastric emptying. However, off treatment, the period of time that the EGJ was in contact with the undiluted layer of gastric secretion was more than twice as long in GERD patients as healthy subjects. This confirms that it is not the volume of gastric secretions per se but rather the distribution of secretions within the proximal stomach that is abnormal in GERD patients and that leads to prolonged exposure of the EGJ to gastric secretions after the meal [12]. It is clear that the proximity of undiluted gastric secretions to a weak, 


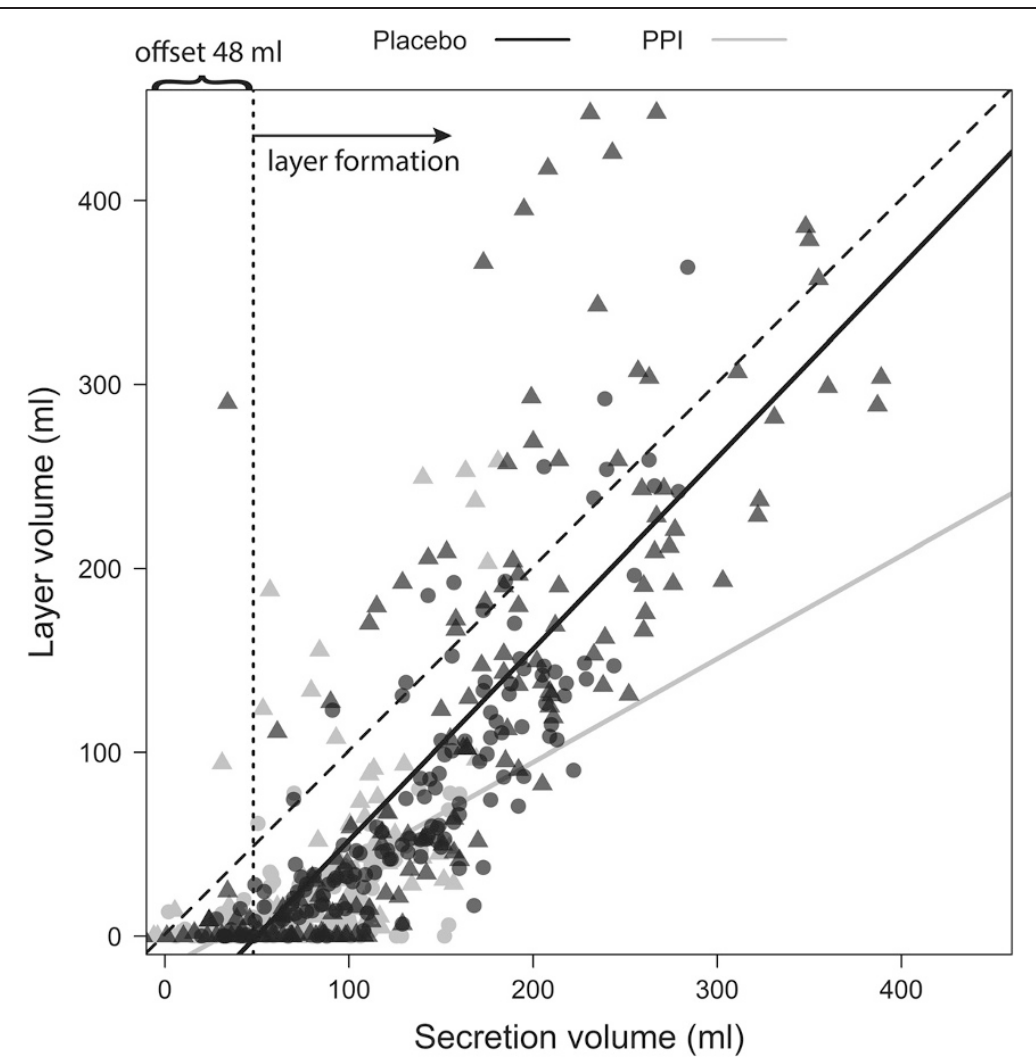

Fig. 6 Correlation of layer and secretion volume under placebo and PPI therapy. GERD and HS data are depicted as triangles and circles, respectively; placebo volumes (black), PPI volumes (grey). The offset in the correlation indicates that layer formation started when approximately $50 \mathrm{ml}$ secretion was present in the stomach. For placebo, the regression coefficient was $R^{2}=0.7$ with regression slope and offset of $1.04 \pm 0.04$ and $-52 \pm 7 \mathrm{ml}$, respectively. On pantoprazole therapy, the regression coefficient was reduced to $R^{2}=0.3$ with regression slope and offset of $0.56 \pm 0.06$ and offset $-18 \pm 5$, respectively

mechanically insufficient reflux barrier in such patients will increase the risk of acid reflux. Consistent with this view, $\mathrm{pH}$-studies have shown that the presence of unbuffered gastric acid adjacent to the EGJ is more important than the size (i.e. length) of the "acid pocket" in determining the risk of reflux $[1,2]$; however, in the absence of an hiatus hernia, these studies could not explain why this occurred. As the volume of secretions is the same in both groups, abnormal distribution of gastric secretions within the stomach must reflect abnormal morphology of the EGJ and proximal stomach in GERD patients. The three-dimensional structure and function of this region in GERD patients has been studied by concurrent MRI and high resolution manometry [22, 23]. This work demonstrated that the esophagogastric insertion angle was obtuse, the insertion of the esophagus into the stomach and the orientation of the proximal stomach within the abdomen are altered in GERD patients even in the absence of hiatus hernia $[24,25]$. The effect of gastric accommodation or motility on the proximal distribution of gastric secretion was not assessed, however, recent papers provide little evidence that accommodation of the stomach (or intra-gastric pressure) is different in health and GERD $[24,26]$.

The second objective was to document the effects of high dose acid suppression by proton pump inhibitors on the volume, distribution and acidity of the gastric secretion layer. The findings of the randomized, placebo-controlled trial demonstrate that after one week of treatment with $40 \mathrm{mg}$ b.i.d. pantoprazole, gastric secretion volume was reduced approximately by $50 \%$ compared to placebo (Table 1 ). The reduction in the volume and thickness of the layer of gastric secretion above the meal and contact time with the EGJ was even more marked, approximately $75 \%$ in both groups. However a distinct layer of undiluted secretion was still visible in almost all subjects despite high dose PPI treatment (Table 1). A recent $\gamma$-scintigraphy study in GERD patients quantified a reduction in the pooling of ${ }^{99 \mathrm{~m}} \mathrm{Tc}$-pertechnetate (a surrogate for chloride ions) of $43 \%$ and a reduction in the cross-sectional area of the acid pocket of $33 \%$ [12]. The larger effects on the acid layer observed in this study can be logically explained by the three-dimensional spatial information 


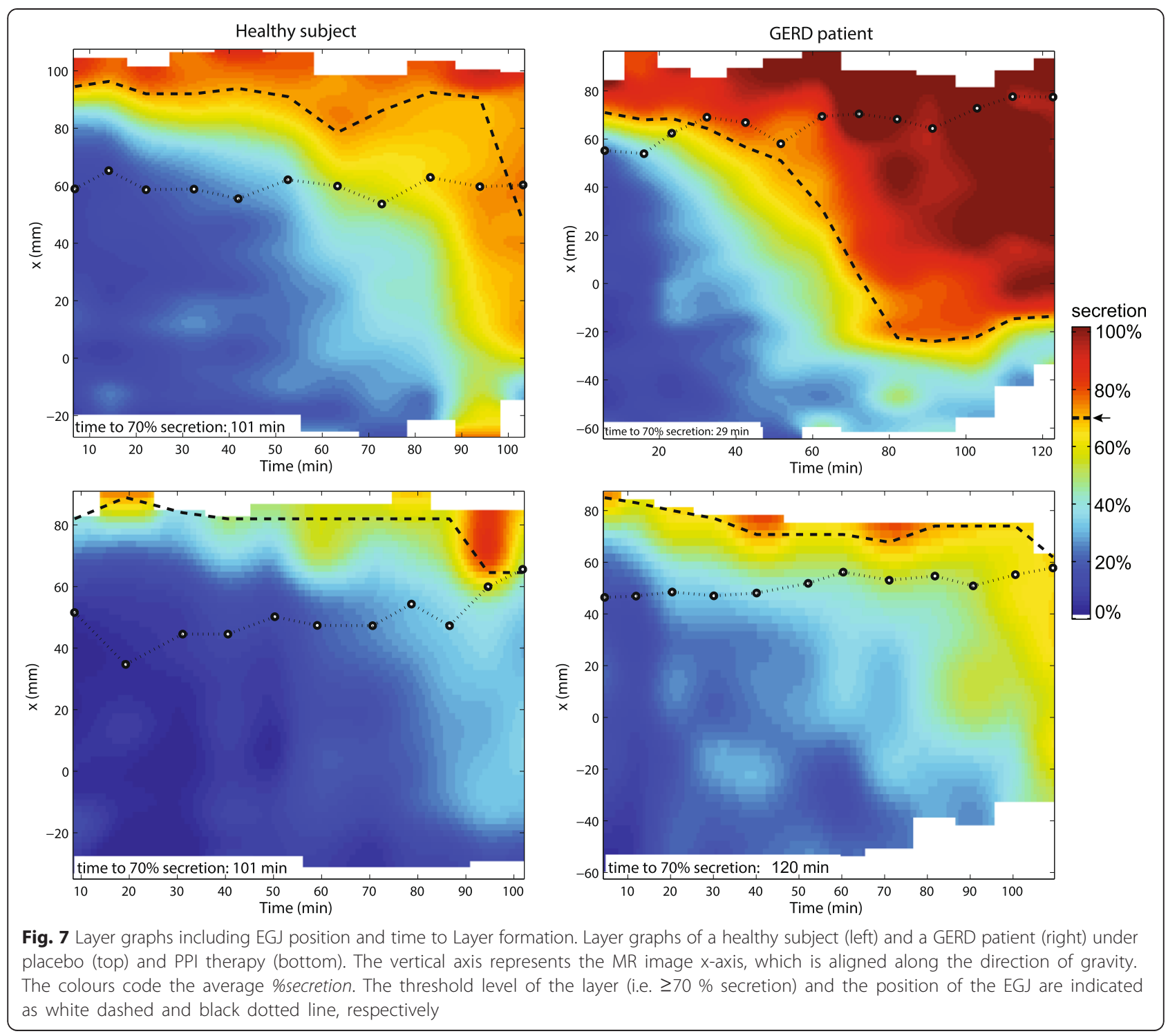

extracted from MRI data, compared to the twodimensional projection information obtained from $\gamma$ scintigraphy.

Intra-gastric $\mathrm{pH}$ monitoring documented that the acidity of the residual layer increased from below $\mathrm{pH} 2$ on placebo to $\mathrm{pH} 4.5 \pm 0.3$ and $3.8 \pm 0.3$ on PPI in healthy subjects and GERD patients, respectively. This is very similar to the results of previous $\mathrm{pH}$ pull-through studies that documented the effects of PPI on the "acid pocket" by $\mathrm{pH}$ pull-through in healthy subjects and GERD patients $[21,27]$. In summary, this study makes clear that the effect of high-dose PPI on acid production is at least an order of magnitude greater than its effects on gastric secretion volume (i.e. $\sim 1 \%$ ongoing secretion of protons (increase of 2 $\mathrm{pH}$ units) vs. $\sim 50 \%$ production of gastric secretion volume on PPI). These findings indicate that suppression of gastric secretion is incomplete and layering of undiluted secretion persists under PPI therapy. Although a recent $\mathrm{pH}$ pull-through and $\gamma$-scintigraphy study found no difference in the position or the $\mathrm{pH}$ of the acid pocket between partial and complete PPI responders [27], reasons for symptom persistence on PPI are varied, and the persistent layer of secretions adjacent to the EGJ seen on MRI provides a ready source of mildly acid reflux $(\sim \mathrm{pH} 4)$ after meals $[1,12]$. In this situation the therapeutic aims of GERD patients with persistent symptoms on acid suppression should not be limited to increasing intra-gastric $\mathrm{pH}$ by further increasing PPI dose. Rather supplementary therapy that involves displacing the layer of secretions away from the EGJ as described in recent studies with raft-forming alginates such as Gaviscon Advance (Reckitt Benckiser, Slough, UK) may provide additional protection from symptomatic reflux from the "acid" or, on PPI, the "mildly-acid" pocket [5, 6, 9, 28]. 
This study demonstrates that combining MRI allows non-invasive assessment of intragastric meal, secretion and $\mathrm{pH}$ distribution at high spatial and temporal resolution. Applied after ingestion of a secretion stimulating test meal, this approach represents an efficient tool to assess the efficacy of pharmaceutical agents and their potential effect on gastric motor and secretory function in general and the "acid pocket" in particular. Our MRI method to assess intragastric secretion meal volumes has been evaluated and applied in previous studies [10, $13,17,18,29,30]$, and has been expanded in this work by the quantification of the secretion layer and its influence by PPI therapy. The unique advantage of this approach is that the distribution and layering of gastric secretion can be visualized and analyzed locally in three-dimensions and directly related to gastric and gastro-esophageal structure and function. Limitations of this technique include the need to study patients lying down in the MRI scanner rather than in the upright position. The location of the gastric secretion layer in the stomach and, thus, EGJ contact time with the layer both vary with body position [31, 32]. This may be due to the morphological changes at the EGJ that favor collection of gastric secretions in this region [29]. Further, current catheter and sensor technology for the measurement of intragastric $\mathrm{pH}$ are not MRI compatible and, thus, required a sequential rather than a combined measurement protocol for MRI and pH-metry. Another issue is that liquid nutrients do not represent a "normal meal"; however, this is necessary to allow estimates of secretion volume and distribution of secretion within the stomach. Note that a previous study demonstrated no difference in acid reflux events between liquid and solid meals with identical nutritional composition [33]. A limitation of the T1 mapping method applied to document secretion is that it does not differentiate between gastric, duodenal or saliva secretion (all exhibit similar T1 values) [13]. To simulate dilution of the labelled test meal by gastric secretion and to correlate meal dilution with intra-gastric $\mathrm{pH}$, an ex vivo titration experiment was performed using $0.1 \mathrm{~N} \mathrm{HCl}^{-}$. A meal dilution of $\geq 70 \%$ gastric secretion per image voxel, which reflected a $\mathrm{pH}$ threshold of $\mathrm{pH} \leq 2$ off PPI, was defined as the secretion layer. Note that, in vivo, the secretion layer can additionally be buffered by substances such as saliva and mucus. Otherwise, the layer $\mathrm{pH}$ can also contain digestive products such as amino acids and free fatty acids and also be contaminated by bile acids. Since simulated gastric fluid including all mentioned factors is not yet available for in vitro digestion [34], the extent by how much these factors may have altered the actual $\mathrm{pH}$ value in the layer remains speculative. Nevertheless, the MRI approximated $\mathrm{pH}$ values were comparable to the actual intragastric $\mathrm{pH}$ documented on sequential $\mathrm{pH}$ studies. An application of the conventional threshold of $\mathrm{pH} \leq 4$ (equivalent to a dilution of $\geq 17 \%$ secretion) used to define the acid pocket in $\mathrm{pH}$ pull-through studies would have had resulted in even larger estimates of intragastric secretion volume and layer thickness.

\section{Conclusions}

This study confirms that a layer of gastric secretion on the surface of gastric contents is always present after meals. The volume of gastric secretion was very similar in healthy subjects and GERD patients; however the distribution of gastric secretions in the stomach was abnormal in GERD patients and resulted in prolonged exposure of the EGJ to unbuffered gastric secretions. This improved on $40 \mathrm{mg}$ pantoprazole b.i.d. but layering of mildly acid secretion at the EGJ persisted in most individuals and this could well represent the source of mildly acid reflux that persists in some patients on high dose PPI treatment. MRI with T1 mapping represents a powerful non-invasive tool for further investigations on therapies targeting the reduction of gastric secretion and reflux from the "acid pocket".

\section{Additional file}

Additional file 1: Details on MRI sequence parameters. MRI sequence parameters of the gastric volume scan were: Steady state free precession sequence (b-FFE); 30 axial image slices; slice thickness $=6 \mathrm{~mm}$; field of view $=360 \mathrm{~mm}$; scan matrix $=240 \times 192$; repetition time $=3.3 \mathrm{msec}$; echo time $=1.5 \mathrm{msec}$; flip angle $=60^{\circ}$; scan time $=15.5 \mathrm{~s}$, one breath hold. MRI sequence parameters of the T1-B1 mapping sequence (gastric secretion scan) were for T1 mapping: Dual flip angle gradient echo sequence, 8 axial image slices, slice thickness $=15 \mathrm{~mm}$, slice gap $=0.5 \mathrm{~mm}$, field of view $=360 \mathrm{~mm}$, scan matrix $=128 \times 128$, repetition time $=9 \mathrm{msec}$, echo time $=3.6 \mathrm{msec}$, flip angles $=5^{\circ}$ and $31^{\circ}$, number of dummy excitations $=29$ and 21, scan time $=15 \mathrm{~s}$, one breath hold. For B1 mapping: Dual repetition time gradient echo sequence, slice thickness $=15 \mathrm{~mm}$, slice gap $=0.5 \mathrm{~mm}$, flip angle $=70^{\circ}$, field of view $=360 \mathrm{~mm}$, scan matrix $=64 \times 64$, repetition time $1(T R 1)=20 \mathrm{msec}$, repetition time $2=100 \mathrm{msec}$, echo time $=3.6 \mathrm{msec}$, number of dummy excitations $=6$, scan time $=54 \mathrm{~s}$, three breath holds. (PDF $70 \mathrm{~kb}$ )

\section{Competing interests}

The authors declare that they have no competing interests.

\section{Authors' contributions}

AS, MS, WS, MFo and MFr designed the research study; AS and MS performed the research, analysed the data and wrote the manuscript; JC and $\mathrm{DL}$ performed the research and analysed the data; DM analysed the data. All authors read and approved the final manuscript.

\section{Acknowledgments}

We would like to thank Brigitta Gabathuler and Diana Jovanovic for technical assistance and Carolin Baruffol for assisting in data analysis. This work was supported in part by a grant from the Olga Mayenfisch Stiftung, Zurich, Switzerland.

\section{Author details}

'Division of Gastroenterology and Hepatology, University Hospital Zurich, Raemistrasse 100, CH-8091 Zurich, Switzerland. Institute for Biomedical Engineering, University and ETH Zurich, Gloriastrasse 35, CH-8092 Zurich, Switzerland. ${ }^{3}$ Menne Biomed Consulting, Olgastr. 7, D-72074 Tübingen, Germany.

Received: 9 June 2015 Accepted: 27 August 2015

Published online: 02 September 2015 


\section{References}

1. Beaumont H, Bennink RJ, de Jong J, Boeckxstaens GE. The position of the acid pocket as a major risk factor for acidic reflux in healthy subjects and patients with GORD. Gut. 2010;59(4):441-51.

2. Clarke AT, Wirz AA, Manning JJ, Ballantyne SA, Alcorn DJ, McColl KE. Severe reflux disease is associated with an enlarged unbuffered proximal gastric acid pocket. Gut. 2008;57(3):292-7.

3. Fletcher J, Wirz A, Young J, Vallance R, McColl KE. Unbuffered highly acidic gastric juice exists at the gastroesophageal junction after a meal. Gastroenterology. 2001;121(4):775-83.

4. Kahrilas PJ, McColl K, Fox M, O'Rourke L, Sifrim D, Smout AJ, et al. The acid pocket: a target for treatment in reflux disease? Am J Gastroenterol. 2013;108(7):1058-64

5. De Ruigh A, Roman S, Chen J, Pandolfino JE, Kahrilas PJ. Gaviscon Double Action Liquid (antacid \& alginate) is more effective than antacid in controlling post-prandial oesophageal acid exposure in GERD patients: a double-blind crossover study. Aliment Pharmacol Ther. 2014;40(5):531-7.

6. Kwiatek MA, Roman S, Fareeduddin A, Pandolfino JE, Kahrilas PJ. An alginate-antacid formulation (Gaviscon Double Action Liquid) can eliminate or displace the postprandial 'acid pocket' in symptomatic GERD patients. Aliment Pharmacol Ther. 2011;34(1):59-66.

7. Rohof WO, Bennink RJ, de Ruigh AA, Hirsch DP, Zwinderman AH, Boeckxstaens GE. Effect of azithromycin on acid reflux, hiatus hernia and proximal acid pocket in the postprandial period. Gut. 2012;61(12):1670-7.

8. Scarpellini E, Boecxstaens V, Farre R, Bisschops R, Dewulf D, Gasbarrini A et al. Effect of baclofen on the acid pocket at the gastroesophageal junction. Dis Esophagus. 2015;28(5):488-95.

9. Thomas E, Wade A, Crawford G, Jenner B, Levinson N, Wilkinson J. Randomised clinical trial: relief of upper gastrointestinal symptoms by an acid pocket-targeting alginate-antacid (Gaviscon Double Action) - a doubleblind, placebo-controlled, pilot study in gastro-oesophageal reflux disease. Aliment Pharmacol Ther. 2014;39(6):595-602

10. Goetze $O$, Treier R, Fox M, Steingoetter A, Fried M, Boesiger $P$, et al. The effect of gastric secretion on gastric physiology and emptying in the fasted and fed state assessed by magnetic resonance imaging. Neurogastroenterol Motil. 2009;21(7):725-e742

11. Kuiken S, Van Den Elzen B, Tytgat G, Bennink R, Boeckxstaens G. Evidence for pooling of gastric secretions in the proximal stomach in humans using single photon computed tomography. Gastroenterology. 2002;123(6):2157-8. author reply 2158

12. Rohof WO, Bennink RJ, Boeckxstaens GE. Proton pump inhibitors reduce the size and acidity of the acid pocket in the stomach. Clin Gastroenterol Hepatol. 2014;12(7):1101-7. e1101.

13. Sauter M, Curcic J, Menne D, Goetze O, Fried M, Schwizer W, et al Measuring the interaction of meal and gastric secretion: a combined quantitative magnetic resonance imaging and pharmacokinetic modeling approach. Neurogastroenterol Motil. 2012;24(7):632-8. e272-633.

14. Babaei A, Bhargava V, Aalam S, Scadeng M, Mittal RK. Effect of proton pump inhibition on the gastric volume: assessed by magnetic resonance imaging. Aliment Pharmacol Ther. 2009;29(8):863-70.

15. Schwizer W, Menne D, Schütze K, Vieth M, Goergens R, Malfertheiner $P$, et al. The effect of Helicobacter pylori infection and eradication in patients with gastro-oesophageal reflux disease: a parallel-group, double-blind, placebocontrolled multicentre study. United European Gastroenterol J. 2013;1(4):226-35.

16. Schwizer W, Thumshirn M, Dent J, Guldenschuh I, Menne D, Cathomas G, et al. Helicobacter pylori and symptomatic relapse of gastro-oesophageal reflux disease: a randomised controlled trial. Lancet. 2001;357(9270):1738-42.

17. Treier R, Steingoetter A, Goetze O, Fox M, Fried M, Schwizer W, et al. Fast and optimized T1 mapping technique for the noninvasive quantification of gastric secretion. J Magn Reson Imaging. 2008;28(1):96-102.

18. Fruehauf H, Menne D, Kwiatek MA, Forras-Kaufman Z, Kaufman E, Goetze O, et al. Inter-observer reproducibility and analysis of gastric volume measurements and gastric emptying assessed with magnetic resonance imaging. Neurogastroenterol Motil. 2011;23(9):854-61.

19. Pinheiro JC, Bates DM. Mixed-Effects Models in S and S-PLUS. New York: Springer; 2000

20. Pandolfino JE, Zhang Q, Ghosh SK, Post J, Kwiatek M, Kahrilas PJ. Acidity surrounding the squamocolumnar junction in GERD patients: "acid pocket" versus "acid film". Am J Gastroenterol. 2007;102(12):2633-41.

21. Vo L, Simonian HP, Doma S, Fisher RS, Parkman HP. The effect of rabeprazole on regional gastric acidity and the postprandial cardia/gastro-oesophageal junction acid layer in normal subjects: a randomized, double-blind, placebocontrolled study. Aliment Pharmacol Ther. 2005;21(11):1321-30.

22. Kaufman E, Curcic J, Pal A, Forras-Kaufman Z, Treier R, Schwizer W, et al. The Structure and Function of the Gastro-Esophageal Junction in Health and Reflux Disease Assessed By Magnetic Resonance Imaging and High Resolution Manometry. Gastroenterology. 2009;136(5):A17-7.

23. Roy S, Fox MR, Curcic J, Schwizer W, Pal A. The gastro-esophageal reflux barrier: biophysical analysis on 3D models of anatomy from magnetic resonance imaging. Neurogastroenterol Motil. 2012;24(7):616-e269.

24. Curcic J, Roy S, Schwizer A, Kaufman E, Forras-Kaufman ZA, Menne D, et al. Abnormal Structure and Function of the Esophagogastric Junction and Proximal Stomach in Gastroesophageal Reflux Disease. Am J Gastroenterol. 2014;109(5):658-67.

25. Curcic J, Schwizer A, Kaufman E, Forras-Kaufman Z, Banerjee S, Pal A, et al. Effects of baclofen on the functional anatomy of the oesophago-gastric junction and proximal stomach in healthy volunteers and patients with GERD assessed by magnetic resonance imaging and high-resolution manometry: a randomised controlled double-blind study. Aliment Pharm Ther. 2014;40(10):1230-40.

26. Pauwels A, Altan E, Tack J. The gastric accommodation response to meal intake determines the occurrence of transient lower esophageal sphincter relaxations and reflux events in patients with gastro-esophageal reflux disease. Neurogastroenterol Motil. 2014;26(4):581-8.

27. Rohof WO, Bennink RJ, de Jonge H, Boeckxstaens GE. Increased proximal reflux in a hypersensitive esophagus might explain symptoms resistant to proton pump inhibitors in patients with gastroesophageal reflux disease. Clin Gastroenterol Hepatol. 2014;12(10):1647-55.

28. Sweis R, Kaufman E, Anggiansah A, Wong T, Dettmar P, Fried M, et al. Post-prandial reflux suppression by a raft-forming alginate (Gaviscon Advance) compared to a simple antacid documented by magnetic resonance imaging and $\mathrm{pH}$-impedance monitoring: mechanistic assessment in healthy volunteers and randomised, controlled, double-blind study in reflux patients. Aliment Pharmacol Ther. 2013;37(11):1093-102.

29. Curcic J, Sauter M, Schwizer W, Fried M, Boesiger $P$, Steingoetter A. Validation of a golden angle radial sequence (GOLD) for abdominal T1 mapping during free breathing: Demonstrating clinical feasibility for quantifying gastric secretion and emptying. J Magn Reson Imaging. 2015;41(1):157-64.

30. Treier R, Steingoetter A, Fried M, Schwizer W, Boesiger P. Optimized and combined T1 and B1 mapping technique for fast and accurate T1 quantification in contrast-enhanced abdominal MRI. Magn Reson Med. 2007;57(3):568-76.

31. Steingoetter A, Fox M, Treier R, Weishaupt D, Marincek B, Boesiger $P$, et al. Effects of posture on the physiology of gastric emptying: a magnetic resonance imaging study. Scand J Gastroenterol. 2006;41(10):1155-64.

32. Treier R, Steingoetter A, Weishaupt D, Goetze O, Boesiger P, Fried M, et al. Gastric motor function and emptying in the right decubitus and seated body position as assessed by magnetic resonance imaging. J Magn Reson Imaging. 2006;23(3):331-8.

33. Fox M, Barr C, Nolan S, Lomer M, Anggiansah A, Wong T. The effects of dietary fat and calorie density on esophageal acid exposure and reflux symptoms. Clin Gastroenterol Hepatol. 2007;5(4):439-44

34. Minekus $M$, Alminger M, Alvito P, Ballance $S$, Bohn T, Bourlieu C, et al. A standardised static in vitro digestion method suitable for food - an international consensus. Food Funct. 2014;5(6):1113-24.

\section{Submit your next manuscript to BioMed Central and take full advantage of:}

- Convenient online submission

- Thorough peer review

- No space constraints or color figure charges

- Immediate publication on acceptance

- Inclusion in PubMed, CAS, Scopus and Google Scholar

- Research which is freely available for redistribution 